\title{
Proactive Strategies to Address Health Equity and Disparities: Recommendations from a Bi-National Symposium
}

\author{
Jeannie Haggerty, PhD, Marshall H. Chin, MD, MPH, Alan Katz, MB ChB, MSc, \\ Kue Young, MD, DPhil, Jonathan Foley, MPA, Antoine Groulx, MD, MSc, FCMF, \\ Eliseo J. Pérez-Stable, MD, Jeff Turnbull, MD, Jennifer E. DeVoe, MD, DPhil, \\ and Uche S. Uchendu, MD
}

Introduction: Health inequities persist in Canada and the United States. Both countries show differential health status and health care quality by social characteristics, making zip or postal code a greater predictor of health than genetics. Many social determinants of health overlap in the same individuals or communities, exacerbating their vulnerability. Many of the contributing factors and problems are structural and evade simple solutions.

Methods: In March 2017 a binational Canada-US symposium was held in Washington DC involving 150 primary care thought leaders, including clinicians, researchers, patients, and policy makers to address transformation in integrated primary care. This commentary summarizes the session's principal insights and solutions of the session tackling health inequities at policy and delivery levels.

Discussion: The solution lies in intervening proactively to reduce disparities-developing risk-adjustment measures that integrate social factors; increasing the socioeconomic, racial, and ethnic diversity of health providers; teaching cultural humility; supporting community-oriented primary care; and integrating equity considerations into health system funding. We propose moving from retrospective analysis to proactive measures; from equality to equity; from needs-based to strengthbased approaches; and from an individual to a population focus. ( $\mathrm{J}$ Am Board Fam Med 2018;31: 479-483.)

Keywords: Administrative Personnel, Canada, Health Status, Primary Health Care, Retrospective Studies, Risk Adjustment

This commentary summarizes the principal insights of the session that addressed equity and disparities at a binational symposium held in Wash-

This article was externally peer reviewed.

Submitted 12 July 2017; revised 8 January 2018; accepted 10 January 2018.

From the Department of Family Medicine, McGill University, Montreal, Canada (JH); Richard Parrillo Family Professor of Healthcare Ethics, Section of General Internal Medicine, University of Chicago, Chicago, IL (MHC); Manitoba Centre for Health Policy \& Professor, Departments of Community Health Sciences and Family Medicine, University of Manitoba, Winnipeg, Canada (AK); School of Public Health, University of Alberta, Edmonton, Canada (KY); Westcott Partners, LLC, Silver Spring, MD (JF); Health Services and University Medicine, Ministère de la Santé et des Services Sociaux, Quebec, Canada (AG); National Institute on Minority Health and Health Disparities, National Institutes of Health, Bethesda, MD (EJP-S); The Ottawa Hospital, Ottawa, Canada (JT); Department of ington, DC on March 2-3, 2017, bringing together US and Canadian health services researchers, clinicians, patients, and decision-makers to share

Family Medicine, Oregon Health \& Science University, Portland, OR (JED); United States Department of Veterans Affairs, Washingtone D.C. (UU).

Funding: Funding for the symposium described in this paper was provided by the following: the Canadian Institutes of Health Research (CIHR), CIHR-Institute of Health Services and Policy Research, North American Primary Care Research Group, ABFM Foundation, Robert Graham Center, College of Family Physicians of Canada, Canadian Strategy for Patient Oriented Research (SPOR), Robert Wood Johnson Foundation, Health Canada, Ontario SPOR Support Unit, Unité de Soutien SRAP Québec, BC SPOR Support Unit, Saskatchewan Center for Patient-Oriented Research, George \& Fay Yee Centre for Healthcare Innovation, Newfoundland and Labrador Support, Academy Health, and Canadian Nurses Association.

Conflict of interest: none declared. 
insights and best practices on transformation in integrated primary care. Although the differences in health care coverage make financial barriers to first contact access to medical services lower for citizens of Canada than of the United States, both countries show differential health status and health care quality by social characteristics ${ }^{1}$, making zip or postal code a greater predictor of health than genetics.

Persisting inequity can be overwhelming. Many problems are structural and evade simple solutions. The macro-economic system creates an increasing wealth gap between rich and poor, as do the incentives and barriers in the health care system. ${ }^{2}$ Payment systems are not explicitly designed to improve health equity, nor are health organizations and plans held accountable for health disparities in their clinical performance measures., ${ }^{3,4}$ Payers are increasingly rewarding providers for achieving measures of clinical quality, consumer satisfaction, and efficient resource use. But achieving target levels of technical quality can be very challenging for providers serving socially vulnerable populations, whose persistent social conditions and limited economic resources place them at high risk of both poor health and poor health care $e^{5,6}$ - populations for whom affordable housing and food security take priority over preventive health screenings and adherence to medications. ${ }^{7,8}$ Many risk factors such as race/ethnicity, socioeconomic status, remoteness, and indigenous status overlap in the same individuals or communities, exacerbating their vulnerability. The limited socioeconomic, racial, and ethnic diversity of health providers limits their ability to understand the issues and intervene effectively.

In this session, 4 presentations on strategies to reduce racial and ethnic disparities in health care delivery (Chin, Katz, Young, Foley) were commented on by 4 discussants, followed by a lively exchange with the audience. Marshall Chin emphasized the need to make equity integral to quality of care, with consequent implications for payment reform and health professional education in the United States. Alan Katz described how partnering with indigenous, First Nations communities in Manitoba, Canada led to a holistic conception of

Corresponding author: Jeannie Haggerty, $P h D, 3830$ Avenue Lacombe, Montréal, QC H3T 1L5, Canada (E-mail: jeannie.haggerty@mcgill.ca). primary health care, with potential to address historic inequities and health system inefficiencies. Kue Young used the case of medical evacuations in the far north of Canada to illustrate a whole-system and network approach to primary care organization, reaching to telecommunication and transport systems. Jon Foley presented New Zealand's primary health care transformation policy with equity considerations at its core. Four discussants commented: Groulx as a policy maker for primary care delivery; Pérez-Stable emphasizing health professional education; Turnbull combining his experience in delivering clinical care to marginalized populations with a role in defining quality of care; DeVoe on harnessing big data to address disparities in family practice. Mentioned solutions included risk adjustment measures that integrate social factors; increasing socioeconomic, racial, and ethnic diversity of health providers; teaching cultural humility; supporting community-oriented primary care; and integrating equity considerations into health system funding. Here, we expand briefly on some of the solutions.

\section{From Retrospective Analysis to Proactive Measures}

Too often, equity is addressed retrospectively. Disparities are observed and bemoaned in the secondary analysis of access, quality, or health outcomes by the social factors mentioned above. But as suggested by Turnbull, DeVoe and others, by making equity integral to our definition of quality of care and by including equity in root cause analyses in quality improvement initiatives, we can move toward provulnerable care delivery. ${ }^{9,10,11}$ Combining these approaches with real-time analyses to track anticipated impact on vulnerable populations may help to better align performance-based remuneration and incentives for those who care for vulnerable populations. ${ }^{12}$

Crucial to integrating equity into quality measurement and producing proactive measures of equity will be systematically identifying social determinants in patient care, integrating them into quality improvement indicators and risk adjustments for funding, and incentivizing the reduction of disparities. ${ }^{8,13-15} \mathrm{We}$ need to agree on a minimal set of metrics that can be captured uniformly so that social determinants can become visible and inform care delivery. We do not advocate setting lower achievement targets for providers serving vulnerable populations, implying 
that these populations may never achieve equal health status, thus cementing historic inequities. Rather, clinicians and organizations should be funded and rewarded for cross-sectoral coordination that addresses social determinants and the reduction of disparities.

\section{Beyond Equality to Equity}

Approaches that deliver equal quantity and/or quality of care to all can leave behind those with more need. An equity orientation requires a provulnerability bias in policies. New Zealand's Primary Health Care Strategy was presented as an example of a provulnerability policy and funding formula. A 10-year life-expectancy gap existed between Maori and European or Asian men in $1999 .{ }^{16}$ Therefore, the Ministry of Health in 2001 established a population-based funding formula that directed additional funding to Primary Health Organizations (PHOs) that served higher numbers of enrollees who identified as Maori, Pacific Island, and/or were residents of the most deprived areas in the country. All PHOs receive funding to reduce the enrollees' cost of receiving general practitioner and practice nurse services. PHOs receive additional funding proportional to the number of vulnerable enrollees for health promotion efforts and to improve access for vulnerable populations including transportation services, nurse clinics on traditional Maori meeting spaces or remote locations, and community health workers. PHOs that serve disproportionately high need populations (more than 50\% Maori, Pacific Island, and/or highest deprivation quintile) receive funding deemed sufficient to offer free or low-cost services for all enrollees. The New Zealand case demonstrates that it is possible to incorporate social determinants into population health funding. Although it remains a challenge to get the right funding formula, e.g. directing funds to evidence-based interventions and rigorously monitoring outcomes, the mechanisms exist and can work where there is political will.

Provulnerability policies also exist in the United States and Canada. In the United States, federally funded community health centers, first established in the 1960s as part of President Lyndon Johnson's Great Society, address social risk factors from a community-oriented primary care perspective. ${ }^{17}$ More than 1200 Health Centers serve disproportionately high numbers of uninsured and lowincome patients. They are governed by boards that include a majority of area residents, and they use provulnerable practices such as community health workers and targeted outreach campaigns. ${ }^{18}$ They provide preventive care and clinically appropriate chronic illness care on par with or better than private providers, even before controlling for the socioeconomic conditions. ${ }^{19,20}$ More recently in 2017, the Center for Medicare and Medicaid Innovation is testing an Accountable Health Communities model of care in 32 communities, where new "bridge" organizations coordinate coalitions of health and social service providers to address health-related social needs such as deficiencies in patient housing, social isolation, lack of adequate transportation, food insecurity, interpersonal violence, utility concerns, and poor coordination with social services for Medicaid, Medicare and dual enrollees. The evaluation of the impact on cost, quality of care, and health outcomes will provide valuable policy lessons in the United States and Canada.

In 2001, the Canadian province of Manitoba introduced the Healthy Baby Prenatal Benefit, where low-income women are eligible for an unconditional income support (up to $\$ 81.41$ Can monthly) during their second and third trimesters. Compared with low-income women who did not apply for or receive the benefit, low-income women who received the income supplement were significantly less likely to have infants with low birth weight, preterm births, or small for gestational age. $^{21}$ The province of Ontario is poised to experiment with a guaranteed minimum income policy, with benefits expected to extend beyond health status. In the United States, interventions such as earned-income tax credit may provide income support.

\section{From Needs-Based to Strength-Based Approaches}

A purely needs-based approach risks confounding social vulnerability with incapacity. Vulnerable populations often demonstrate resourcefulness, resilience, and social cohesion that can be leveraged to address their needs and improve wellbeing. Combining needs assessment with a strength-based analysis requires health care organizations and providers to have respectful relationships with communities, and to use methodologies that are sensitive to culture and values. Recognition of community strengths and available resources is the first step to collaboratively establishing common goals and un- 
derstanding community needs. ${ }^{22}$ For example, despite the long history of abuse at church-run residential schools, some Canadian First Nation communities identify themselves strongly with the Church and Christian values. Others find their strength from traditional practices and customs. Failure to recognize these sources of strength and wholeness may lead to importing culturally inappropriate interventions that may even cause harm.

Identifying strengths and leveraging resources may be more challenging in areas that are culturally, racially and religiously heterogeneous, as in core areas of large cities. Whatever the challenges, working effectively with communities means relinquishing some control. Often the needs and metrics the community chooses are different from what clinicians or planners want them to have. Being part of the solution means recognizing that our unexamined internal biases have been part of the problem; we need the humility to sit, listen, and be partners, and to have the courage to fail at times.

\section{From Individual to Population Focus}

Integrating social determinants into clinical assessments and identifying and harnessing community resources and strengths will require a population focus. We need to better integrate primary care and public health care. ${ }^{23}$ A primary care policy-maker discussant (Groulx) mused that integrating public health workers into the interdisciplinary primary care team could help providers feel more empowered and effective in addressing social and health needs. Actionable public health data could help primary care practices address the needs of catchment populations, even as detailed as "in that highrise apartment building." Combining community vital signs-aggregated community-level information about social deprivation and associated chronic disease risks-with social determinants will enable providers to take action at both the individual and population level. ${ }^{24,25}$

Someone asked, "Who owns the problem of health and health care inequity?" We all own a piece of the problem. Yet, this solution-focused exchange created optimism for the way forward, affirming that we all also own part of the solution. We can make progress on enhancing equity by developing risk-adjustment measures that integrate social factors, making equity intrinsic to quality, increasing the social diversity of health providers, practicing cultural humility, supporting community-oriented primary care, and integrating equity into formulas for health system funding. Working toward equity will also recapture providers' and policy-makers' intrinsic motivation to make a difference in the health and wellbeing of the individuals and communities they serve.

To see this article online, please go to: http://jabfm.org/content/ 31/3/479. full.

\section{References}

1. Lasser KE, Himmelstein DU, Woolhandler S. Access to care, health status, and health disparities in the United States and Canada: Results of a crossnational population-based survey. Am J Public Health 2006;96:1300-7.

2. Woolf SH, Braveman P. Where health disparities begin: The role of social and economic determinants-And why current policies may make matters worse. Health Affairs 2011;30:1852-9.

3. Chin MH. Creating the business case for achieving health equity. J Gen Intern Med 2016;31:792-6.

4. DeMeester RH, Xu LJ, Nocon RS, Cook SC, Ducas AM, Chin MH. Solving disparities through payment and delivery system reform: A program to achieve health equity. Health Aff (Millwood) 2017;36: 1133-9.

5. Aday LA. At risk in America: The health and health care needs of vulnerable populations in the United States. San Fransisco, CA: John Wiley \& Sons; 2002.

6. Mechanic D, Tanner J. Vulnerable people. Groups, and populations: societal view. Health Aff (Millwood) 2007;26:1220-30.

7. Centers for Medicare \& Medicaid Service. Comprehensive Primary Care Plus $(\mathrm{CPC}+)$ fact sheet. Centers for Medicare \& Medicaid Service. 2016. Available from: https://www.cms.gov/Newsroom/ MediaReleaseDatabase/Fact-sheets/2016-Factsheets-items/2016-04-11.html. Accessed July 2017.

8. Joynt KE, De Lew N, Sheingold SH, Conway PH, Goodrich K, Epstein AM. Should Medicare valuebased purchasing take social risk into account? N Engl J Med 2017;376:510-3.

9. Chin MH. Moonshots, opioids, and incentives. The Health Care Blog. December 8, 2016. Available from: http://thehealthcareblog.com/blog/2016/12/ 08/moonshots-opioids-and-incentives/.

10. Lynn J, Straube BM, Bell KM, Jencks SF, Kambic RT. Using population segmentation to provide better health care for all: the "Bridges to Health" model. Milbank Q 2007;85:185-208.

11. Organization for Economic Cooperation and Development (OECD). Rising to the global challenge: Partnership for reducing world poverty. Statement by the Development Assistance Committee High Level Meeting. Organization for Economic Coop- 
eration and Development (OECD), April 25-26, 2001, Paris, France.

12. Porter ME, Pabo EA, Lee TH. Redesigning primary care: A strategic vision to improve value by organizing around patients' needs. Health Aff (Project Hope) 2013;32:516-25.

13. Gottlieb L, Tobey R, Cantor J, Hessler D, Adler NE. Integrating social and medical data to improve population health: Opportunities and barriers. Health Aff (Millwood) 2016;35:2116-23.

14. DeVoe JE, Bazemore AW, Cottrell EK, et al. Perspectives in primary care: A conceptual framework and path for integrating social determinants of health into primary care practice. Ann Fam Med 2016;14:104-8.

15. Accounting for social risk factors in medicare payment: Criteria, factors, and methods. Washington, DC: National Academies Press; 2016 Jul 13.

16. Ajwani S, Blakely T, Robson B, Tobias M, Bonne M. Decades of disparity: Ethnic mortality trends in New Zealand 1980-1999 Ministry of Health and University of Otago. Public Health Intelligence Occasional Bulletin Number 16. Wellington, New Zealand: Ministry of Health; July 2003.

17. Geiger HJ. The first community health centers: A model of enduring value. J Ambul Care Manage 2005;28:313-20.

18. Institute for Alternative Futures. Community health centers leveraging the social determinants of health. Alexandria, VA: Institute for Alternative Futures. March 2012.
19. Goldman LE, Chu PW, Tran H, Romano MJ, Stafford RS. Federally qualified health centers and private practice performance on ambulatory care measures. Am J Prev Med 2012;43:142-9.

20. Dor A, Pylypchuck Y, Shin P, Rosenbaum SJ. Uninsured and Medicaid patients' access to preventive care: Comparison of health centers and other primary care providers. (Geiger Gibson/RCHN Community Health Foundation Research Collaborative policy research brief no. 4). Washington, DC: George Washington University, School of Public Health and Health Services, Department of Health Policy; 2008.

21. Brownell MD, Chartier MJ, Nickel NC, et al. Unconditional prenatal income supplement and birth outcomes. Pediatrics 2016;137:e20152992.

22. Michener JL, Koo D, Castrucci BC, Sprague JB. The practical playbook: Public health and primary care together. New York, NY: Oxford University Press; 2015.

23. Institutes of Medicine PC. Public health: Exploring integration to improve population health. Washington, DC: Institute of Medicine; 2012.

24. Hughes LS, Phillips RL Jr, DeVoe JE, Bazemore AW. Community vital signs: Taking the pulse of the community while caring for patients. J Am Board Fam Med 2016;29:419-22.

25. Bazemore AW, Cottrell EK, Gold R, et al. "Community vital signs": Incorporating geocoded social determinants into electronic records to promote patient and population health. J Am Med Inform Assoc 2015;23:407-12. 